\title{
Retention of pharmaceutical residues: the example of the Altendorf retention soil filter
}

\author{
E. Christoffels \& F. M. Mertens \\ Erftverband, Bergheim, Germany
}

\begin{abstract}
A study has been conducted on a retention soil filter (RSF) to test its effectiveness in removing pharmaceutical residues from combined sewer overflows (CSO). Efficient removal of solids, nutrients and heavy metals has already been proven by Frechen (Neue Erkenntnisse zur Mischwasserbehandlung in Retentionsbodenfiltern, 2012). The possibility that organic micropollutants are also retained by the use of retention soil filters has been identified, but data is lacking. Results obtained in this study, in which testing for removal by RSF of numerous micropollutant substances has been performed, are most promising. The pharmaceuticals diclofenac and ibuprofen are presented in detail as examples of such micropollutants. Both show a reduction in positive samples of more than $55 \%$ as well as a significant reduction in median and maximum concentrations. These results add to the evidence that using retention soil filters in the advanced treatment of wastewater from combined sewer overflows reduces the exposure of watercourses to pharmaceutical residues.

Keywords: retention soil filter, combined sewer overflow, micropollutants, pharmaceuticals, diclofenac, ibuprofen.
\end{abstract}

\section{Introduction}

In addition to hydraulic impulsion loads on receiving watercourses, overflows from combined sewer systems induce significant substance loads [2]. Nevertheless, there are currently no mandatory regulations in Germany to limit such emissions. One reason for this may be that so far only a few systematic monitoring programs for the evaluation of substances contained in combined 
sewer discharges have been carried out. In previous studies the number of parameters examined and the density of the collected data have often been insufficient, and organic micropollutants have hardly been taken into account.

The present study has been conducted as part of a research project funded by the German state of North Rhine-Westphalia (NRW). The overall project entails examination of all relevant pathways for important substance groups, including selected micropollutants, in the catchment of a stream called the Swist, within the basin of the Erft river (a Rhine tributary). Within this project, a program to monitor combined sewer overflows was initiated. It was found that CSO represent a major source of micropollutants in watercourses [3]. It was thought that an appropriate measure to reduce such pollution would be advanced treatment using retention soil filters. One RSF had already been installed in the Swist catchment as a means of advanced treatment of CSO. The excellent cleaning capacity of RSF had already been the subject of past studies, with nutrient retention rates of $75 \%$ and $98 \%$ reported $[4,5]$. Studies undertaken by the authors delivered similar results. The scope of this paper is thus limited to the methods applied and results obtained in the study of micropollutant removal by RSF.

\section{Retention soil filter and the watercourse}

RSF are installed as a measure to treat wastewater from CSO and thereby reduce hydraulic stress and pollutant load in a watercourse. The holding back of combined sewage from direct discharge attenuates the hydraulic load for the receiving watercourse. In the filter combined sewage percolates through a soil layer consisting of filter sand (layer thickness $0.7-1.0 \mathrm{~m}$ ) which is planted with reeds and then flows into an underlying drainage system. When the water exits the RSF it has been filtered physically and purified biochemically [6]. The technical specifications of the RSF considered in this report are listed in Table 1.

Table 1: Altendorf RSF, technical data.

\begin{tabular}{|l|c|c|}
\hline Parameter & Unit & Extent \\
\hline Volume & $\mathrm{m}^{3}$ & 782 \\
\hline Filter area & $\mathrm{m}^{2}$ & 707 \\
\hline Filtering performance (maximum) & $\mathrm{L} / \mathrm{s} / \mathrm{m}^{2}$ & 0.03 \\
\hline Filtering performance (normal operation) & $\mathrm{L} / \mathrm{s} / \mathrm{m}^{2}$ & 0.015 \\
\hline Throttle discharge (maximum) & $\mathrm{L} / \mathrm{s}$ & 21 \\
\hline Throttle discharge (normal operation) & $\mathrm{L} / \mathrm{s}$ & 10.5 \\
\hline Filter sand layer $(0$ - 2 mm) & $\mathrm{m}$ & 0.75 \\
\hline Planting & & $\begin{array}{c}\text { Reed } \\
\text { (Phragmites australis) }\end{array}$ \\
\hline Volume storage sewer (upstream RSF) & $\mathrm{m}^{3}$ & 143 \\
\hline
\end{tabular}


The RSF was built in 2005 and is located near the village of Altendorf, $15 \mathrm{~km}$ from the city of Bonn. The connected combined sewer system provides drainage for the villages of Hilberath and Altendorf, with a total of around 1650 inhabitants. The runoff area is 18.8 ha. The sewer system serves a predominantly rural residential area with some farms. No significant commercial/industrial sites or facilities with special wastewater, such as hospitals, exist. A storage sewer lies upstream of the RSF. When capacity of the sewer system and storage sewer is exceeded due to heavy precipitation, combined sewage flows into the RSF.

After treatment in the RSF, combined sewage is then discharged into a creek called the Altendorfer Bach, which flows into the Swist. The Altendorfer Bach is classified as a siliceous low mountain watercourse rich in fine material [7]. The mean water runoff upstream of the outlet of the RSF amounts to $26 \mathrm{~L} / \mathrm{s}$ (result of rainfall-runoff simulation). Figure 1 shows the Altendorf RSF and the Altendorfer Bach near the RSF outlet.

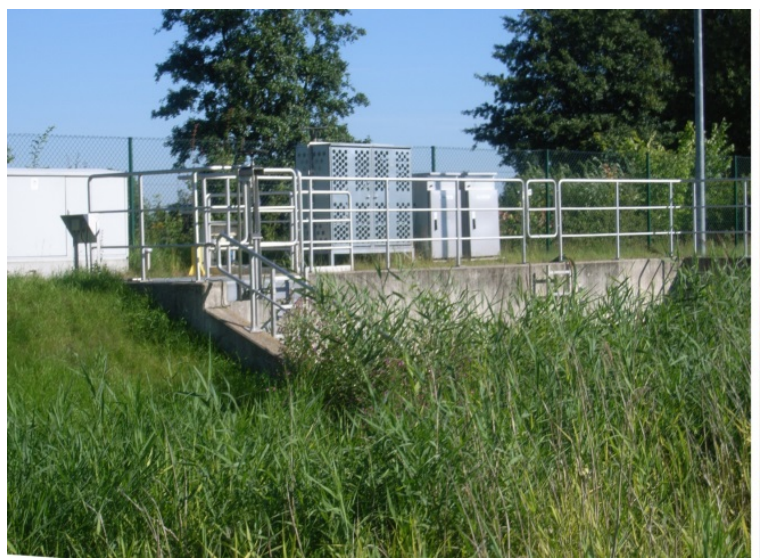

(a)

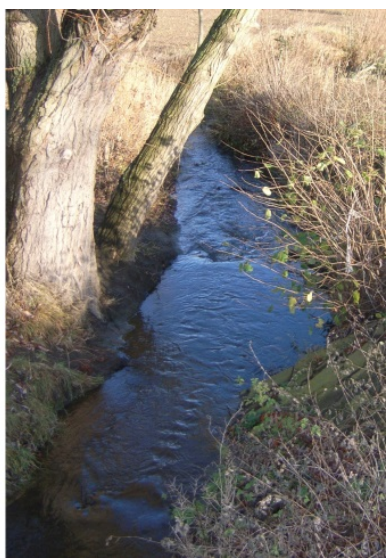

(b)

Figure 1: Inlet area of the Altendorf RSF (a) and Altendorfer Bach at the level of the RSF outlet (b).

\section{Sampling system and analysis}

At the inflow of the Altendorf RSF a water level sensor registers the beginning of the discharge from the sewer storage to the RSF. Here a system is also installed which automatically detects RSF filling and triggers a sampling procedure. Automatic sampling devices, each equipped with eleven bottles, are installed at both the inlet and outlet of the RSF. The sampling procedure is controlled by a programmable logic controller (PLC), which allows individual programming of sample filling. For each RSF filling event, twelve minute composite samples of 2.9 liters over a maximum of 132 minutes are collected from the inflow and, with a time delay of one hour to account for the retention 
time in the RSF, from the outflow. This ensures that residual water from the previous filling event has left the filter before the beginning of the next sampling. When sampling starts, notification is automatically sent to the staff via SMS to ensure rapid collection and analysis. The samples thus obtained are tested for a wide variety of parameters (Table 2).

Table 2: Scope of physico-chemical investigations (overview).

\begin{tabular}{|c|c|c|}
\hline Physico-chemical parameters & Pesticides & Pharmace uticals \\
\hline Filterable solid & $2,4,5-\mathrm{T}$ & Bezafibrat \\
\hline Filtrate annealing residue & 2,4-D & Carbamazepin \\
\hline Filtrate dry residue & 2,4-DB & Clofibrin acid \\
\hline Conductivity & Atrazin & Diclofenac \\
\hline $\mathrm{pH}$-value & Chloridazon & Fenoprofen \\
\hline Acid capacity 4.3 & Chloroxuron & Gemfibrozil \\
\hline TOC & Chortoluron & Ibuprofen \\
\hline $\mathrm{NH}_{4}-\mathrm{N}$ & Cyanazin & Iminostilben \\
\hline $\mathrm{NO}_{2}-\mathrm{N}$ & Desethylatrazin & Naproxen \\
\hline $\mathrm{NO}_{3}-\mathrm{N}$ & Desethylterbuthylazin & Pentoxifyllin \\
\hline $\mathrm{N}_{\text {organic }}$ & Desisopropylatrazin & \\
\hline $\mathrm{N}_{\text {total }}$ & Dichlorprop & \\
\hline o-PO4-P & Diuron & \\
\hline$P_{\text {total }}$ & Fenoprop & \\
\hline $\mathrm{Ca}$ & Hexazinon & \\
\hline $\mathrm{Mg}$ & Isoproturon & \\
\hline $\mathrm{K}$ & Linuron & \\
\hline $\mathrm{Na}$ & MCPA & \\
\hline $\mathrm{Cl}$ & MCPB & \\
\hline $\mathrm{SO}_{4}$ & MCPP & \\
\hline $\mathrm{Al}$ & Metamitron & \\
\hline $\mathrm{Fe}$ & Metazachlor & \\
\hline $\mathrm{Mn}$ & Metabenzthiazuron & \\
\hline $\mathrm{Ni}$ & Metobromuron & \\
\hline $\mathrm{Zn}$ & Metolachlor & \\
\hline $\mathrm{Pb}$ & Metoxuron & \\
\hline $\mathrm{Co}$ & Metribuzin & \\
\hline $\mathrm{Cd}$ & Monolinuron & \\
\hline $\mathrm{Cu}$ & Monuron & \\
\hline \multirow[t]{6}{*}{$\mathrm{Cr}$} & Prometryn & \\
\hline & Propazin & \\
\hline & Sebuthylazin & \\
\hline & Simazin & \\
\hline & Terbuthylazin & \\
\hline & Terbutryn & \\
\hline
\end{tabular}


The measured values of 30 physico-chemical parameters, 35 pesticides and 10 pharmaceuticals are determined for each sample. The microbiological analyses include twelve parameters.

\section{Results and discussion}

In the period from June 2010 to August 2011, using the sampling system described above, 33 RSF filling events with 343 individual samples were recorded. General physico-chemical parameters and micropollutant substances present at the RSF inlet and outlet were examined. The findings for the pharmaceuticals diclofenac and ibuprofen are considered to be representative. These two pharmaceuticals are widely used as analgesics (painkillers) and to treat inflammation and fever. Figure 2 shows the concentrations of diclofenac and ibuprofen for the inflow and the outflow of the Altendorf RSF. Median values and the 25th and 75th percentiles are depicted as boxes (interquartile range). The ends of the lines represent minimum and maximum values. For values below the limit of quantification $(0.1 \mu \mathrm{g} / \mathrm{L})$, half the detection limit is used as a minimum. In addition, the proportions of the samples above the limit of quantification are given in the figure.

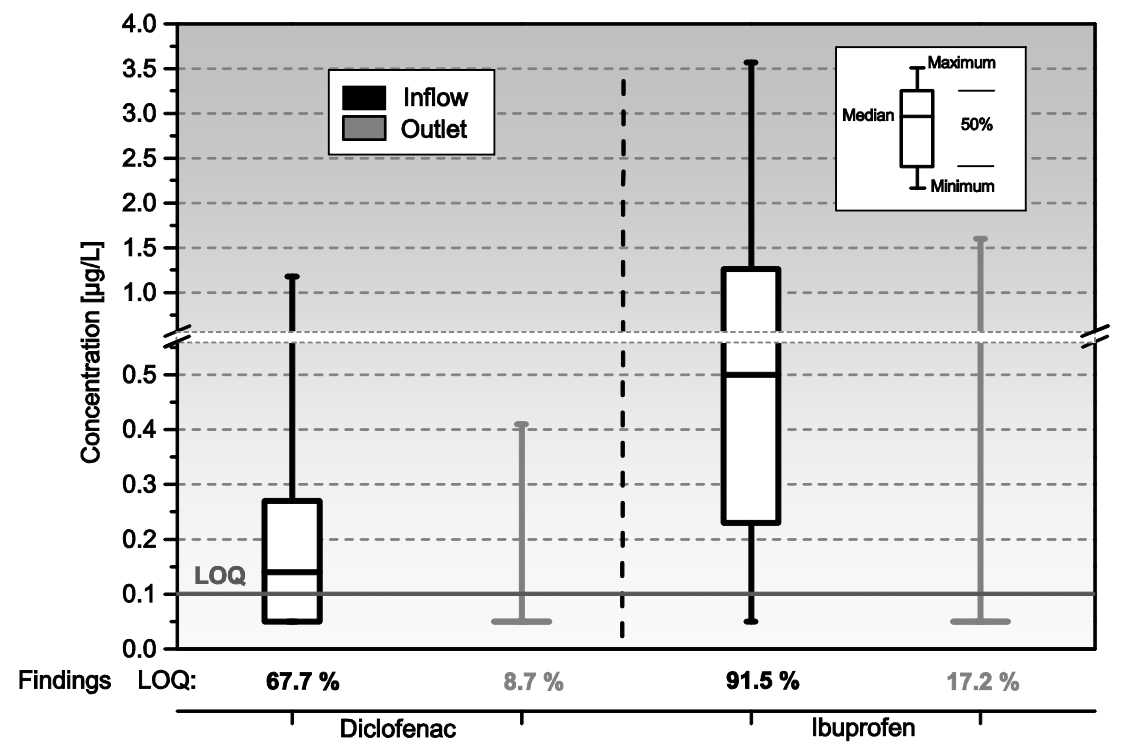

Figure 2: Diclofenac and ibuprofen at the inlet and outlet of RSF Altendorf, measuring data from July 2010 to August 2011, 33 events with 343 individual samples, limit of quantification $(\mathrm{LOQ}=0.1 \mu \mathrm{g} / \mathrm{L}$, assumption: values $<$ LOQ equal to $1 / 2 \mathrm{LOQ}$ ). 
In the RSF inflow diclofenac was detected in $68 \%$ of the samples and ibuprofen in more than $90 \%$. Diclofenac was measured in concentrations up to $1.18 \mu \mathrm{g} / \mathrm{L}$ and ibuprofen up to $3.57 \mu \mathrm{g} / \mathrm{L}$. The RSF retention capacity can be determined by comparing inflow and outflow concentrations. The median diclofenac concentration of $0.14 \mu \mathrm{g} / \mathrm{L}$ has been reduced through RSF treatment to a level below the limit of quantification. Also for ibuprofen significant reduction has been found, from the median concentration of $0.50 \mu \mathrm{g} / \mathrm{L}$ at the inlet to median values below the detection limit at the outlet. Likewise, maximum concentrations have been decreased by $65 \%$ for diclofenac and $55 \%$ for ibuprofen. Furthermore, the number of positive findings at the outlet compared to the inlet has been reduced from $68 \%$ to $9 \%$ for diclofenac and from $92 \%$ to $17 \%$ for ibuprofen.

The results show that the Altendorf RSF effectively retains pharmaceutical residues carried in combined sewage. Average concentrations and the number of positive findings for diclofenac and ibuprofen are reduced remarkably. The significantly lower maximum concentrations at the RSF outflow also indicate that peak concentrations have been capped.

For solids and substances adsorbed on solids first flush effects (higher concentrations at the start of the event due to washout effects) have been described for combined sewer overflows [1]. Because of the high temporal resolution of the samples collected in the monitoring program, statements about the temporal fluctuation of the concentration level during RSF feeding can be made. Figure 3 shows the median values and the 25 th and 75 th percentiles of pharmaceutical concentrations at the inlet and outlet of the Altendorf RSF during the loading phase.
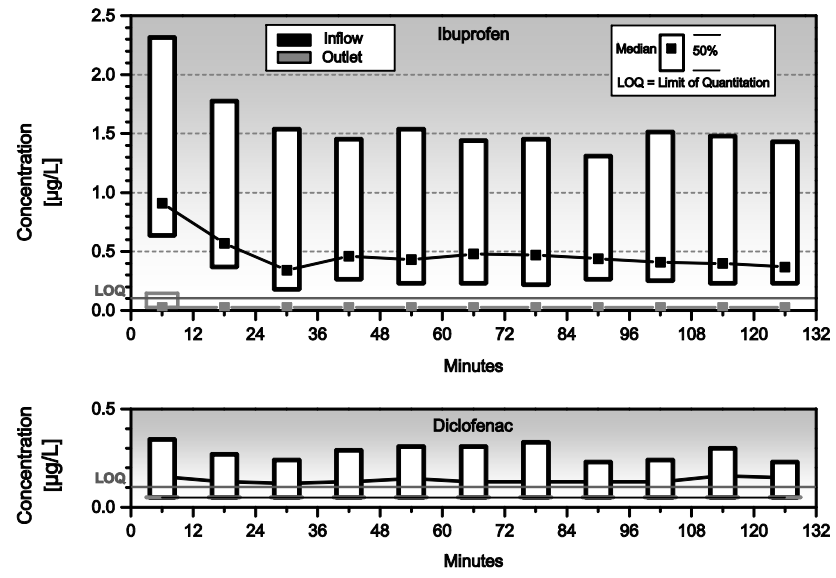

Figure 3: Diclofenac and ibuprofen at the inlet and outlet of RSF Altendorf during the loading phase, from July 2010 to August 2011, 33 events with 343 individual samples, limit of quantification (LOQ $=0.1 \mu \mathrm{g} / \mathrm{L}$, assumption: values $<$ LOQ equal to $1 / 2 \mathrm{LOQ})$. 
At the entrance to the RSF, ibuprofen has been observed in higher concentrations in the first 24 minutes of the examined events than in the further temporal course of the inflowing combined sewage. For the first twelve minutes, a median inlet concentration of $0.91 \mu \mathrm{g} / \mathrm{L}$ has been obtained. For the next time span the median value for ibuprofen has been steady at $0.57 \mu \mathrm{g} / \mathrm{L}$. After that, the median values of the overflow events have fluctuated between 0.35 and $0.50 \mu \mathrm{g} / \mathrm{L}$. The scatter of interquartile values has fluctuated between $1.39 \mu \mathrm{g} / \mathrm{L}$ and $0.86 \mu \mathrm{g} / \mathrm{L}$ for ibuprofen in the inflow. In the RSF outflow, ibuprofen was detectable only sporadically in the first measurement cycle. The 75 th percentile for the first measurement cycle, at $0.14 \mu \mathrm{g} / \mathrm{L}$, stands just above the limit of quantification. For the remaining time window, all values are below the detection limit.

While first flush effects are noticeable for ibuprofen in the inflow, no increased initial concentrations have been detected for diclofenac. In the feed to the RSF, median concentrations for diclofenac are in a range of 0.1 to $0.2 \mu \mathrm{g} / \mathrm{L}$, a significantly lower level than for ibuprofen. Similarly, the scattering of the interquartile values, with a maximum of $0.3 \mu \mathrm{g} / \mathrm{L}$, is less pronounced. In the outflow all percentile values have been, without exception, below the limit of quantification. The results show that the RSF can effectively retain pharmaceutical residues present in combined sewage in a highly stable manner over the entire feed time.

\section{Discharge into the watercourse}

The monthly average runoff of the Altendorfer Bach at the level of the RSF outlet amounts to only $26 \mathrm{~L} / \mathrm{s}$. Without the RSF, the average volume of discharge would be at $100 \mathrm{~L} / \mathrm{s}$ in the case of overflow from the combined sewage system. So, during overflow events, discharge of combined sewage amounts to nearly $80 \%$ of the total runoff of the Altendorfer Bach. The hydraulic impulsion load for the watercourse would also be far greater without the Altendorf RSF, since combined sewer overflows with discharge peaks up to $1000 \mathrm{~L} / \mathrm{s}$ have been observed. The throttle outflow of the RSF flowing into the Altendorfer Bach typically amounts to only $10.5 \mathrm{~L} / \mathrm{s}$ (see Table 1 ). The total volume of discharge and the associated substance loads are greatly reduced through operation of the RSF. Without RSF operation, an average diclofenac concentration of $0.12 \mu \mathrm{g} / \mathrm{L}$ and ibuprofen concentration of $0.40 \mu \mathrm{g} / \mathrm{L}$ would become apparent downstream in the watercourse due to CSO. In accordance with the European Environmental Quality Standard (EQS) for surface waters, diclofenac will be included in a socalled "watch list" of emerging pollutants, with an EQS of $0.1 \mu \mathrm{g} / \mathrm{L}$, and could one day be placed on the priority list [8,9]. As median concentrations for diclofenac and ibuprofen in RSF outflow are below the detection limits, it is presumed that the RSF discharge does not contribute to possible pharmaceutical residues in the receiving watercourse. 


\section{Conclusion}

Wastewater discharges from combined sewer overflows substantially contribute to pollution of watercourses with pharmaceutical residues. The present study shows that the substance load of pharmaceuticals in combined sewer overflows is significantly reduced by advanced treatment with retention soil filters. Watercourses receiving treated combined sewage are noticeably relieved of pollutant loads, and it is expected that increased application of retention soil filters will help to meet future environmental quality standards for micropollutants.

\section{Acknowledgements}

The above study was conducted within the research project entitled "Evaluation of measures to reduce physical, chemical and microbiological loads in rivers with the example of the Swist river". This project is funded by the Ministry for Climate Protection, Environment, Agriculture, Conservation and Consumer Protection of North Rhine-Westphalia. The authors wish to express their gratitude for this support. Thanks also go to our colleagues A. Brunsch, O. Altunay, R. Krump and J. Wunderlich-Pfeiffer, who have contributed their time and effort to carrying out the monitoring program and data analysis.

\section{References}

[1] Frechen, F. B., Neue Erkenntnisse zur Mischwasserbehandlung in Retentionsbodenfiltern: Leistungsfähigkeit, Nährstoffe, Hygiene, DWA Entwässerungskonzepte, 397 S., Hennef., ISBN 978-3-942964-35-7, 2012.

[2] Christoffels, E., Monitoring und Modellanwendung - Entwicklung eines Immissionsinventars am Beispiel der Erft. Erftverband, Bergheim, ISBN 978-3-00-024445-2, 2008.

[3] Kistemann, T., Koch, C., Classen, T., Rechenburg, A., Kramer, F., Herbst, S., Franke, C., Rind, E., Höser, C., Exner, M., Christoffels, E., Krump, R., Willkomm, M, Thormann, D., Hiller, A. \& Lindner W., Mikrobielle Fließgewässerbelastungen durch abwassertechnische Anlagen und diffuse Einträge. Ministerium für Umwelt, Naturschutz, Landwirtschaft und Verbraucherschutz NRW, Online http://www.umwelt.nrw.de/umwelt /pdf/mikro.pdf, 2009.

[4] Ministerium für Umwelt, Naturschutz, Landwirtschaft und Verbraucherschutz NRW, Retentionsbodenfilter - Handbuch für Planung, Bau und Betrieb. Düsseldorf, ISBN: 978-3980861716, 2003.

[5] Frechen, F.-B., Retentionsbodenfilter in Hessen. Wasser-Abwasser-Umwelt Band 29, Kassel University Press, ISBN 978-3899586046, 2010.

[6] Dittmer, U., Prozesse des Rückhaltes und Umsatzes von Kohlenstoff- und Stickstoffverbindungen in Retentionsbodenfilter zur Mischwasserbehandlung. TU Kaiserslautern, 2006. 
[7] http://www.flussgebiete.nrw.de/index.php/Ma\%C3\%9Fnahmenprogramm/ Planungseinheiten/PE_ERF_1400/Steckbrief_Druck, Jan. 2014.

[8] European Commission, Proposal for a Directive of the European Parliament and of the Council amending Directives 2000/60/EC and 2088/105/EC as regards priority substances in the field of water policy, COM (2011) 876 final 2011/0429 (COD), Online http://eur-lex.europa.eu/LexUriServ/site/ de/com/2011/com2011_0876de01.pdf, 2012.

[9] Surface waters: 12 new controlled chemicals, three pharmaceuticals on watch list, Plenary sessions [02-07-2013 - 13:04] Press release, Reference No:20130701IPR14760, Press switchboard number (32-2) 2833000. 